\title{
Los consultorios emocionales: notas para un análisis de la educación sentimental en México en las primeras décadas del siglo $\mathrm{XX}^{1}$
}

\author{
Lonely hearts columns: Notes for an analysis of sentimental education in Mexico at the beginning of the 20th \\ century
}

Oliva López Sánchez

Facultad de Estudios Superiores Iztacala, Universidad

Nacional Autónoma del México, México

olivalopez@unam.mx

DOI: https://doi.org/10.24215/2314257Xe109

Recepción: 31 Diciembre 2019

Aprobación: 12 Febrero 2020

\section{Resumen:}

El artículo analiza la función social de los consultorios emocionales en el México de principios de siglo XX. Estos espacios públicos a cargo de "expertos" atendieron las tribulaciones de la vida emocional conformando una educación sentimental diferenciada por sexo. El consejo experto contribuyó al cultivo de las relaciones afectivas con énfasis en las parejas. A partir del enfoque sociocultural de las emociones, los consultorios amorosos permiten conocer el ethos terapéutico y los valores ético-morales, de acuerdo con los roles de género e identidades sociales, que requirieron de una emocionalidad diferenciada de sectores medios e intermedios en el México prerevolucionario.

Palabras clave: Consultorios emocionales, Educación sentimental, Consejo experto, Ethos terapéutico, Manejo emocional.

\begin{abstract}
:
The article analyzes the social function of Lonely Hearts newspaper columns in Mexico at the beginning of the 20th century. These public spaces of "experts" dealt with the tribulations of emotional life, forming a public sentimental education differentiated by sex. Their "expert" advice contributed to the cultivation of affective relationships for the heterosexual couple. Based on the sociocultural approach to the emotions, Lonely Hearts columns provide valuable insight into everyday social relationships, the therapeutic ethos and ethical-moral values, in accord with gender roles and social identities, which for the middle and upper classes in pre-revolutionary Mexico, required a differentiated emotionality.
\end{abstract}

KEYWORDS: Lonely hearts columns, Emotional life, Expert advice, Therapeutic ethos, Emotional management.

\section{INTRODUCCIÓN2}

El yo, ${ }^{3}$ la entidad más importante de la modernidad, ha implicado el desarrollo de una afectividad particular. En la vida contemporánea, el yo se manifestó cada vez más en la esfera pública. Las relaciones económicas y sociales paulatinamente fueron adquiriendo un carácter emocional implicado en la moda y el consumo como lo ha señalado Simmel (2014) al referir que la moda cumple la función psíquica de fundirnos con el grupo social de pertenencia a partir de la imitación, mientras que las relaciones íntimas cada vez se han ido definiendo por modelos económicos y políticos de negociación e intercambio. Para el caso de la cultura norteamericana del siglo XX, Sterns (1994) ha señalado el surgimiento de una nueva emocionología o estilo emocional caracterizado por un manejo emocional a partir de nuevas habilidades para gestionar el dolor, los celos, el amor, entre otras emociones.

Esta transición y cambio social invitan a una reflexión genealógica del proceso acerca de cómo una subjetividad se tecnificó o materializó, de ahí que sea importante plantear varias preguntas, para intentar un acercamiento histórico a lo que estoy denominando, retomando a Pedraza (2000), educación sentimental, es decir, iniciativas político-sociales, educativas y culturales que buscan ampliar la sensibilidad del individuo en el contexto mexicano. 
Históricamente, la vida emocional ha pertenecido a la esfera psicológica, pero es -en mayor medidauna dimensión de la cultura y lo social, porque las emociones son, de acuerdo con Illouz, la energía de la acción social que "implica al mismo tiempo cognición, afecto, evaluación, motivación” (2007, p. 15), además de los significados culturales del cuerpo y el sexo-género, que no pueden quedar fuera. Las emociones se reconfiguran de acuerdo con el tiempo histórico y el contexto (Sterns y Sterns, 1985); de ahí que, para los enfoques constructivistas y culturalistas, son significados culturales y relaciones sociales que están fusionados. Esta unión les confiere su carácter enérgico, prerreflexivo y, a menudo, semiconsciente (Illouz, 2007).

Las características de la vida emocional en México a principios del siglo XX se configuraron sobre la base del sujeto moral autónomo del llamado hombre nuevo, ${ }^{5}$ léase ser humano (López, 2019). Este imaginario social nació de la mano del modelo económico y social en los Estados nacionales y representó la garantía de una vida moral encauzada por y para el bien del México moderno sustentado en un proyecto de ingeniería social. El proyecto de nación en México implicó la conformación de una subjetividad basada en la raza y la eugenesia social, como en el resto de América Latina (Stepan, 1991).

El desarrollo de la sensibilidad y del mundo interior en el mundo occidental otorgó, en consecuencia, un lugar preponderante al yo, como una instancia psíquica constitutiva del sujeto moderno. El amor a la pareja (amor romántico con base en la libre elección de la pareja) y a la familia se convirtieron en las principales fuentes del yo, en tanto que la vida privada se consideró el espacio idóneo para cultivar dicha sensibilidad.

La formación del alma y la conciencia, la regulación higiénica del cuerpo, la organización de los espacios habitacionales, los métodos pedagógicos, la división sexual del trabajo, la jerarquía social, el uso del tiempo y la orientación estética y sensible han sido fundamentales en la configuración de esa subjetividad moderna, y, con ello, la disposición de una vida emocional implícita. La subjetividad moderna no solo se construyó a partir de los saberes expertos que promovieron formas de conocimiento de sí -tecnologías del yo, como les denominó Foucault (1990)-, basadas en el proyecto de forjar ciudadanos bajo las normas de urbanidad y el control de vida orientada al progreso de la nación (Pedraza, 2000); también participaron distintas instancias e instituciones para el modelamiento de esa subjetividad. Por ello, como lo ha señalado Illouz (2010) y Huertas (2012), se requiere rebasar conceptos generalizadores -vigilancia, biopolítica, gubernamentalidad-, que, si bien han ofrecido datos importantes sobre el disciplinamiento de los cuerpos, no toman en cuenta la complejidad de lo social ni la agencia de los sujetos -capacidades críticas de los actores-, para entender el proceso de lo que podemos llamar estructura del sentimiento (Williams, 2009), cultura emocional (Hochschild, 2008), regímenes emocionales y emotives ${ }^{6}$ (Reddy, 2001), estilo emocional o ethos terapéutico (Illouz, 2010), para dar cuenta de cómo ciertas prácticas, ideas y significados se estabilizan con el tiempo en la cultura y orientan la vida cotidiana, dando lugar a una educación sentimental.

De acuerdo con los argumentos esgrimidos, el objetivo central de este manuscrito es reflexionar sobre los llamados consultorios amorosos o sentimentales en el México de principios de siglo XX. Estos espacios públicos construidos y mantenidos para atender las tribulaciones de la vida emocional, conocida como vida del corazón o lenguaje del corazón, nos permiten profundizar en el análisis de las emociones y en el ethos terapéutico, que fue conformando de manera procesual un estilo de vida que sirvió para fortalecer el cultivo de la vida amorosa y de las relaciones afectivas en general, contradictorias o no, siempre en consonancia con el proyecto social y los valores de la sociedad en la que son analizados dichos escenarios.

Como un caso específico, se revisa la sección "Consultas", firmada por Alina, de la página Para las Damas, del semanario Actualidades, fundado en el año de 1909. A través de las respuestas que esta sección daba a sus lectores se busca profundizar en la construcción del sujeto moderno y su vínculo afectivo con el mundo social, a partir de sus emociones y la performatividad que estas suponen en la conformación de sus roles e identidades de género (Reddy, 2001). El análisis propuesto se enfoca en recuperar el manejo emocional referido a tres ámbitos: maternidad y crianza, el amor y la amistad entre mujeres y hombres. Se privilegian las prescripciones emocionales de acuerdo con el género de un estrato social intermedio y medio urbano de la Ciudad de México, público al que estuvo dirigido el semanario. 
El consejo fue un recurso vertebral en la construcción del sujeto moral autónomo y representa una oportunidad para conocer las relaciones sociales cotidianas y los valores ético-morales que han de revelarse, de acuerdo con los roles de género e identidades sociales, que, según Illouz (2007), requieren de una emocionalidad diferenciada para hacer posible su concreción, ya que las emociones tienen una función performativa al igual que el género (Reddy, 2001).

\section{LA VIDA DEL CORAZÓN: ALGUNOS ANTECEDENTES}

Las sociedades burguesas europeas de los siglos XVIII y XIX ofrecieron una diversidad de posibilidades para el encauzamiento del mundo interior y el desarrollo de una sensibilidad que ha de reflejarse, como asegura Pedraza (2000), en la escritura de diarios íntimos, cartas, novelas con mensajes morales edificantes, que dibujaban relaciones sociales idealizadas en cuanto al sexo, la clase y el cultivo-orientación de las emociones.

Esta idea de concebir la vida emocional en la sociedad ilustrada europea de los siglos XVIII y XIX posibilitó el desarrollo de lo que dio por llamarse lenguaje del corazón, el cual penetró en América Latina y en México con sus particularidades. Con ello, la variabilidad léxica y de significado del mundo afectivo-emocional (emociones, sentimientos, pasiones y afectos) guardan sentidos y concepciones distintas que dependen del contexto y el tiempo. Como apunta Bolufer (2016), sus sentidos se encubren y se combinan para definirse entre sí. En otros momentos, se puede identificar su clara interpretación religiosa, moral o fisiológica, pero siempre con una intención social más amplia que merece ser trabajada.

El lenguaje del corazón se difundió a través de los géneros literarios, específicamente de tipo sentimental, que se aprecian en la literatura de ficción, el teatro, las novelas o relatos breves. Paulatinamente, fueron teniendo mayor presencia en la prensa periódica y la literatura edificante para niños, jóvenes y mujeres. De igual forma, como asegura Bolufer (2016) - por hallazgos propios-, la psiquiatría y la psicología de finales del siglo XIX y principios del XX otorgaron un lugar preponderante a la sensibilidad de los sujetos para definir la enfermedad mental, porque las emociones se vincularon con la dimensión moral y psíquica, que daba cuenta de la salud emocional de los individuos (López, 2019).

El interés del estudio de la vida sensible o emocional de los sujetos hacia finales del siglo XIX y las primeras décadas del XX, en Europa como en América Latina, específicamente México, requiere ser analizado en contrapunto con los discursos políticos y los proyectos de homogeneización y regeneración de la raza -en su dimensión física, cultural y lingüística-. Estos discursos igualmente pretendieron edificar valores patrióticos basados en el bien común, el desarrollo, la unidad y la productividad, y estuvieron dirigidos también a una naciente clase media orientada por la moda y el consumo (López, 2019). Por lo que hemos asegurado, el proyecto nacional mexicano tiene una lectura en clave emocional que debe ser profundizada.

El foco de los discursos $p s i^{7}$ (Rose, 1999) -dirigido principalmente a controlar las pasiones y luego las emociones del loco- paulatinamente fue ampliando sus coordenadas no solo para definir al enfermo, sino, sobre todo, para construir la subjetividad moderna. Por ello, es frecuente encontrar en las publicaciones periódicas una alta proliferación de secciones basadas en datos psicológicos sobre las buenas costumbres, el matrimonio, el amor, la sexualidad, los comportamientos esperados de una dama y un caballero, el arreglo de la casa, el vestido o la comida. Estos y otros ámbitos de la vida privada se hacían públicos y se traducían en emociones, como la ternura y el cuidado otorgado por las mujeres en sus roles de madre-esposas, el amor por la familia y la patria, el orgullo y la amistad en los hombres, porque había una estrecha relación entre la vida íntima y los valores de la civilidad que despuntaban en el siglo XX. Una nueva gestión emocional se hacía necesaria y la prensa cumplió la función de educadora sentimental a falta de espacios pedagógicos formales (López, en prensa).

Durante la etapa finisecular del XIX y las primeras décadas del XX proliferaron un sinfín de revistas para mujeres letradas de la clase alta y media, literatura edificante por entregas para ellas, así como opúsculos, publicados y distribuidos por la librería de Ch. Bouret, que comunicaban modelos idealizados de feminidad 
y que abarcaban a todos los estratos sociales. Esto se debió a que conservadores y liberales compartían la representación de la mujer como un ser liminal en términos morales, que requería orientación experta educación- para encauzarla en una vida sin vicios, ni enfermedades (López, 2009, 2019).

\section{LA PRENSA ORIENTADORA DE UNA SENSIBILIDAD}

La prensa ${ }^{8}$ fue otro medio importante para la educación sentimental en el México de principios del siglo XX (Castro, González y Masera, 2013; Cornejo, 2016). Periódicos, pasquines, gacetillas y hojas volantes llegaron a toda la población, incluida la analfabeta, ${ }^{9}$ porque estas publicaciones se acompañaban de imágenes y grabados para comunicar sus contenidos, tanto sensacionalistas de la nota roja, como orientaciones domésticas y consejos para el cortejo que se trasmitían de boca en boca y en la figura del lector-escucha en las plazas públicas (Speckman, 2001; Castro, González y Masera, 2013; López, 2018, 2019).

De acuerdo con algunos especialistas, los últimos diez años del porfiriato se consideran los inicios de la prensa y el periodismo moderno en México. Algunos periódicos, como El Imparcial-fundado en 1896 por Rafael Reyes Spíndola-, se consideraron los más modernos, al adoptar el modelo clásico estadounidense: secciones, servicios noticiosos, recursos técnicos, fotografías en primera plana, equipo de reporteros y un departamento de publicidad que transformó el concepto de comercialización (Ortiz y Duarte, 2010). La prensa de esa época incorporó una mirada moderna y científica. Los periódicos, muchos de ellos de vida breve y contestatarios, tenían una línea político-intelectual que incorporaba, además, secciones sobre literatura, notas hechas por gacetilleros sobre la vida cotidiana, historietas y poemas (Ortiz y Duarte, 2010), sin faltar la literatura edificante dirigida a los niños y las mujeres.

Algunos periódicos contaban con secciones exclusivas para las mujeres; otros, los menos, como El Mundo Ilustrado, ${ }^{10}$ incluyeron apartados para los hombres. Los temas de la vida cotidiana se comunicaban con mensajes sobre la base de principios morales y religiosos, con un cariz científico-intelectual que, por sus contenidos, buscaba inculcar formas de sentir vinculadas con las virtudes morales diferenciadas por sexo, clase social y educación. ${ }^{11}$ Sin importar la línea editorial -conservadora o liberal-, el imaginario sobre la vida íntima y la mujer, como el sujeto moral, era similar. Se abarcaban temas como crímenes, suicidio, infidelidad, celos, sexualidad, viudez, abandono, amistad, educación de los hijos, familia, divorcio, salud e higiene, enfermedades de tipo sexual, alcoholismo y no faltaban los llamados crímenes pasionales.

Tampoco faltaban los consejos de belleza para las mujeres, para el cortejo o para conservar el matrimonio y la moda. Las publicaciones incluyeron, junto con los poemas, sátiras y caricaturas sobre el amor conyugal. Comenzaron a aparecer los espacios de consulta en los que hombres y mujeres dirigían cartas y preguntas a los expertos, esperando una respuesta certera a los sinsabores de "la vida del corazón". Las columnas con este tipo de consultas aparecieron en las páginas junto con noticias de la vida social de países europeos y Estados Unidos. Los anuncios de productos y servicios en gran formato acompañaron las publicaciones periódicas; claramente se fue estimulando una cultura de moda y consumo de la naciente clase media como parte de la construcción de la subjetividad modernista, y la comercialización se reforzaba más y más, como lo ha señalado Simmel (2014).

Actualidades ${ }^{12}$ fue una publicación inicialmente semanal, de distribución nacional, y respondía al régimen del presidente Porfirio Díaz. Era considerada por sus editores, Alfonso E. Bravo y Luis Lara y Pardo, como "el periódico de la vida moderna”. Apareció en enero de 1909 y en junio dejó de publicarse. La edición se reanudó el 15 de octubre de ese año, pero ya como un "diario político independiente". ${ }^{13} \mathrm{El} 15$ de diciembre cerró definitivamente. La publicación trataba temas diversos nacionales e internacionales (Méndez, 2001), estaba dirigida a sectores intermedios -obreros y del sector servicios- y medios -intelectuales y sectores instruidoscomo los denomina Bastian (1989). Abarcaba a un público urbano letrado y liberal y a una clase obrera en ascenso. 
La página 3 era "Para las Damas", a cargo de escritores hombres y algunas mujeres, versaba sobre temas de higiene personal, adornos para la casa, asuntos de la moral, historias edificantes por entregas, recetas útiles, consejos domésticos y cosméticos para mantener la belleza. Se incluían recomendaciones para que las mujeres siempre fueran amadas y detallaban las cualidades físicas y morales que las hacían atractivas para los hombres. Esta página promocionaba productos y servicios modernos como modista a domicilio, grabados y retratos para las damas, reflexiones sobre la vida en la ciudad. Resulta fundamental analizar la mezcla de información, entre moda, belleza y consejos, porque hay un claro mensaje sobre el tránsito de, como sostiene Simmel (2014), de una identificación de la vida en grupo a la vida individual de la modernidad, caracterizada por la relevancia del agrado y lo efímero. Al mismo tiempo, la moda promueve la imitación en el consumo de productos y orientará de manera precisa a las mujeres a través de los consejos, formas de gestionar sus emociones basadas en un autocontrol, para mantener sus relaciones amorosas de pareja y maternales. Luego de retomar las tesis de Sterns (1994) y Simmel (1994), puedo afirmar que la moda y el consejo buscaban orientar la individualidad, valor fundante del capitalismo y la vida moderna.

\section{CONSULTORIOS EMOcIONALES: LA NECESIDAD DE ORIENTAR LA VIDA ÍNTIMA EN PRO DEL SUJETO MORAL}

El consultorio amoroso o sentimental ha sido definido como "un espacio mediático dedicado íntegramente a la evaluación de problemas sentimentales que se intentan solucionar mediante una serie de recomendaciones" (Garis y Tardón, 2008, p. 89) ${ }^{14}$ Entre 1900 y 1920 la prensa modernista en México incluyó secciones y columnas en las que su objetivo exprofeso fue la invitación a establecer una abierta comunicación pública con las lectoras y lectores, para que estos se animaran a enviar consultas sobre penas, gozos, deseos, confidencias, o simples dudas a una "amiga querida" para tratar temas del corazón:

¿Habéis oído alguna vez, lectoras mías, hablar y discurrir sobre el interesante problema de las amistades incógnitas ó lejanas? Seguramente que sí, pues tan sugestivo asunto ha preocupado más de una vez á sutiles ingenios é inspirados escritores.

Sin conocer aún vuestra opinión, me atrevo á asegurar que creéis en esos poéticos y sinceros lazos, como creo yo y como probablemente creen casi todos los espiritus del sexo débil. Las almas femeninas nos acogemos siempre á todas esas comunicaciones delicadas y espirituales con hondo respeto y profunda fe, encontrando en ellas algo atractivo y encantador con que entretener la loca fantasía que nuestra imaginación se empeña en desarrollar, á pesar de las resistencias que opone nuestro raciocinio (Actualidades, página "Para las Damas", sección “Consultas”, 15 de octubre de 1909, p. 3 [cursivas añadidas]).

Se trató de una invitación para compartir emociones, buscar consejos y tener una escucha amistosa y comprensiva:

\footnotetext{
Admito, pues, el supuesto de que tanto vosotras como yo creemos en las dulces comunicaciones con personas á quienes no conocemos más que por escrito, vengo hoy á haceros una visita en estas breves líneas, esperando que no tardaréis en correspondérmela, confiándome vuestras penas, vuestros goces ó simplemente vuestras dudas ó deseos. Yo acudiré gustosa á vuestro llamado siempre que solicitéis mi ayuda en esta página, procurando dejaros complacidas. Y cuando tengáis alguna confidencia dolorosa que hacerme, estad segura de que mi alma abrirá sus puertas de par en par y recibirá vuestra visita como la de una amiga querida (Actualidades, página Para las Damas, sección “Consultas”, 15 de octubre de 1909, p. 3).
}

Estas columnas periodísticas representan un espacio público, anónimo, de consulta emocional al servicio de mujeres de la ciudad -aunque no faltaban por ello los hombres-, de sectores sociales medios e intermedios, alfabetizadas. El amor de pareja y maternal dejó de ser una experiencia exclusiva de las clases acaudaladas para convertirse en una aspiración social de los sectores medios y trabajadores.

La sección de consultas o consejos en los diarios se fundamentó en la importancia de "los recursos de la amistad" (Actualidades, página "Para las Damas", sección “Consultas”, 16 de octubre de 1909, p. 3), una figura fundamental en las recomendaciones para la vida íntima, principalmente de las mujeres y la construcción de su subjetividad. Los consultorios amorosos representan la inauguración de un espacio liberal 
de recomendaciones basadas en la moral secular y en la amistad como un valor y como una relación social que consolida lazos y vínculos emocionales, a la vez que articula una subjetividad y un despliegue de pensamientos, creencias y acciones colectivas de la vida privada de las mujeres.

\section{Alina: la amiga Consejera del Periódico ACtualidades}

En la página "Para las Damas", del semanario Actualidades, la sección de "Consultas", firmada por Alina, ofreció orientación sobre distintos temas, principalmente de la vida amorosa, de relaciones amistosas, filiales o de pareja:

¡Cuántas veces, cuántas estaréis solas en vuestra alcoba ó en el gabinete de labor, bordando, al par que la tela prisionera en vuestros dedos, los maravillosos encajes que el ensueño teje y borda en el fondeo del corazón! Tan pronto será un crepúsculo violeta y oro que contempléis desde la abierta ventana festoneada por la yedra, y allá, muy lejos, entre los lejanos horizontes, un peregrino fatigado y nostálgico, que se llama el "ideal”, pasará por vuestra puerta, tal vez sin entrar ni detenerse en ella... Luego desaparecerá esta visión para presentarse ante vuestros deslumbrados ojos otra no menos bella...Es un parque lejano y frondoso (...) La vida se desliza entre ellos. Sólo que no siempre son risueños ni halagadores: otras veces son fúnebres presagios y dolorosas remembranzas. En unos y en otros se anhela siempre la dulce confidencia ó la sabrosa plática, para compartir la propia emoción con otro sér á quien podamos hacer participe de nuestras impresiones.

Cuando una ú otra cosa queráis, lectoras mías, os repito que siempre os escuchará con vivo interés (Actualidades, página Para las Damas, sección “Consultas”, 15 de octubre de 1909, p. 3) [cursivas añadidas]).

Los temas frecuentemente consultados a Alina fueron los relacionados con amor, celos, vínculo amoroso, amistad, rechazos, engaños, maltratos, edad, belleza, amor y moral, regalos, arreglo de la casa, de los niños, entre otros. De los diversos temas que se abordaron en la columna, se retoman tres: la maternidad y crianza, el amor y la amistad entre mujeres y hombres.

\section{MATERNIDAD Y CRIANZA}

Las mujeres jóvenes solicitaban a Alina ideas para llevar una casa. En sus respuestas se observan los valores conservadores de sectores sociales medios respecto de los roles que debían desempeñar las mujeres, basados en lo que se entendió como la renuncia al egoísmo en favor de su rol de ama de casa:

Para ser buena ama de casa lo primero que se necesita es abnegarse de un modo completo en favor de todos aquellos seres que están al cuidado de dicha ama. De modo que la propia personalidad sea la que se coloque al último, tanto en las atenciones como en las comodidades. Para servir, atender y educar á los demás es preciso que el egoísmo desaparezca (Actualidades, página Para las Damas, sección "Consultas”, 10 de noviembre de 1909, p. 3 [cursivas añadidas]).

La maternidad fue sobre todo un clúster de emociones que debían conjugarse para hacer posible el rol de madre y sentir la maternidad: renunciar al egoísmo de las necesidades de las mujeres -cualesquiera que fueran en el sentido personal-, entrega absoluta a los hijos, amor y ternura para cuidarlos en todos los aspectos. Lo que para las mujeres representó la exigencia del manejo emocional para ajustarse a lo que Sterns (1994) llamó estilos emocionales (Sterns, 1994), promovidos por los discursos expertos, defensores de un proyecto social progresista sustentado en la funcionalidad de la familia.

El rol de ama de casa y madre también se orientó sobre la responsabilidad directa de la mujer como la encargada de la higiene y la educación, dos valores en favor de la clase media.

Después, conservar la casa en buen orden, vigilando por sí misma á los criados, sin dejar este cargo en manos ajenas; y, por último, el cuidado más prolijo debe ser para los niños, atendiendo debidamente su higiene y limpieza sin dejar para más tarde la educación, la cual, según una opinión autorizada, debe comenzar con la misma edad del niño. Estos cuidados requieren la atención completa de la madre, en todos los momentos (Actualidades, página Para las Damas, sección "Consultas", 10 de noviembre de 1909 , p. 3). 
Claramente el consejo anterior refiere a una mujer de clase alta, de quien se exigía la presencia y el cuidado directo de sus hijos, lo cual perfilaba una modificación en las relaciones familiares de estas mujeres, que hacia finales del siglo XIX eran apoyadas por nodrizas y nanas en las labores de la maternidad (López, 2004).

Otros consejos abarcaron a estratos sociales intermedios. Por ejemplo, en las recomendaciones sobre el tipo de vestido y material del mismo se deja ver esta mirada más democrática de la maternidad como una preocupación nacional:

En cuanto á la manera de vestir á niños tan pequeños como son los que usted me indica, me atrevo á aconsejarle que, si sus recursos son modestos, prefiera las telas lavables, como el bombasí, la franela y el piqué, pues las sedas, aun cuando hay algunas que pueden lavarse, siempre desmerecen al hacerlo, y los niños necesitan, como primera condición para aparecer elegantes, una limpieza absoluta. El color blanco es el más apropiado para ellos y con lo que se ven más lindos (Actualidades, página Para las Damas, sección “Consultas”, 10 de noviembre de 1909, p. 3).

Resulta interesante señalar que, de acuerdo con las respuestas de Alina, podemos identificar que fueron las mujeres jóvenes alfabetizadas quienes formularon las consultas sobre cómo atender a los niños y llevar una casa. Estas mujeres jóvenes parecían preocupadas por desempeñar su rol de madres de una manera eficiente y apegada a los designios de la modernidad. Principios provenientes de la medicina higienista, y afines con los valores que esta especialidad promovió como parte de la garantía moral: limpieza, salud, temperancia y moderación de las conductas relacionadas con el comer, beber, las diversiones y la sexualidad (Jagoe, 1998; López, 2007).

\section{EL VALOR DE LA AMISTAD}

La exaltación de cierto tipo de relaciones sociales, como la amistad, orientaba estilos emocionales como sostiene Sterns (1994). Una nueva emocionología exigía el manejo emocional diferenciado por sexo, edad y estatus social. Las respuestas de Alina diferenciaron los rasgos de amistad entre mujeres, y entre mujeres y hombres. Los primeros fueron, como ya se ha mencionado, un valor fundamental de confianza y lealtad femenina, mientras que la amistad entre un hombre y una mujer se valoró diferente porque se aseguraba que siempre conllevaba a un interés mayor de tipo sentimental amoroso y una etapa previa a cualquier relación cariñosa formal o no:

Si después de esta indagación, hecha prudente y discretamente, resulta que su silencio no obedece á una causa grave, le aconsejo, por bien suyo, que no piense más en el amigo ausente, y le retire, en su interior, esa amistad tan sincera y profunda con que le ha distinguido, pues seguramente él no ha sabido comprenderla. (Actualidades, página Para las Damas, sección "Consultas", 10 de diciembre de 1909, p. 3).

La amistad entre las mujeres era un valor inquebrantable que debía anteponerse por encima del amor a un hombre:

Es de lamentarse que haya usted encontrado en su camino una alma tan igual á la suya y á la vez tan adicta, cuando la circunstancia de haberse él dirigido á la amiga de usted solicitando su amor hace que esa amistad particular, tan deseada por el caballero en cuestión y por usted, sea imposible entre los dos, por impedirlo la completa sinceridad que usted debe á su amiga, la cual no vería con buenos ojos esa amistad tan tierna y delicada entre su novio y su amiga predilecta.

Me dice usted que no se trata de amores, es verdad; pero puedo asegurarle que esas amistades tan vehementes entre personas de distinto sexo, nunca están exentas de algún matiz amoroso, el cual no debe existir entre ustedes, pues ofendería cruelmente á la que usted llama su "hermana" (Actualidades, página Para las Damas, sección "Consultas", 22 de octubre, 1909, p. 3).

De acuerdo con los consejos de Alina, la amistad entre mujeres representaba una lealtad y una relación más duradera entre iguales, que exigía del sacrificio y la renuncia de intereses, incluso por el mismo hombre:

No querida Lidia; sacrifique usted el delicado placer sentimental que la suerte le brinda, en aras de un deber muy dulce, aunque por ahora le parezca á usted su cumplimiento muy amargo. Créame: entre la amistad amorosa del amigo recién 
venido y la amistad fraternal con la amiga de la infancia, prefiera á ésta, pues el tiempo transcurrido y la fidelidad probada con hechos, en todos los momentos difíciles de la vida, no se sustituyen con nada (Actualidades, página Para las Damas, sección "Consultas", 22 de octubre, 1909, p. 3).

Las amistades constituyeron el respaldo moral y orientadoras de decisiones familiares fundamentales, sobre todo entre las personas de cierto estatus y edad en la vida de los más jóvenes:

Julieta.- Si los padres de usted se oponen á las relaciones amorosas que desde pequeña tiene con su novio, solamente por la antigua enemistad que existe entre la familia de su prometido y la de usted, me parece injusta y poco razonable dicha oposición; sería conveniente que usted intentara obtener el permiso de sus padres para celebrar su matrimonio por medio de la influencia y prestigio de alguna persona autorizada, amiga de los padres de usted: si ni aun de este modo consigue usted su objeto, no le queda ya otro recurso, desde el momento en que es usted mayor que de edad, que acudir á la protección de las leyes, para verificar su enlace, al cual sólo la exaltación indebida de pasados disgustos puede oponerse con tanta falta de prudencia y de razón (Actualidades, página Para las Damas, sección “Consultas”, 21 de noviembre de 1909, p. 3 [cursivas añadidas]).

La amistad entre hombres se veía quebrantada cuando se interesaban por la misma mujer. Dicho interés podía acabar en tragedia, porque se superponían otros valores y emociones por encima de la amistad: el prestigio y la honra masculina, que, por los consejos de Alina se deduce debían ser motivo de respeto en sus relaciones con otros hombres. En este conflicto la mujer debería conducirse con cautela, cuidando el buen nombre del hombre sobre todo si se trataba del esposo:

Carlota. -No me extrañó su carta; la esperaba, siempre que usted no tomase una resolución pronta y enérgica.

La desgraciada circunstancia de haberse enfermado el señor esposo de usted, hizo, en verdad, difícil, que el amigo traidor fuese lanzado de la casa por usted, -pues su desaparición hubiera sido inexplicable para el enfermo.

Sin embargo, ya ve usted cuán urgente es que el fingido amigo no vuelva á visitarla, pues esa amenaza de suicidio qué efectuó en presencia de usted, pudo ser de gravisimas consecuencias, tanto para su reputación como para las relaciones con el señor su esposo. Si el tiro hubiera salido, ¿se imagina usted el escándalo que hubiera ocurrido, y el susto y sorpresa inevitables que habría llevado el enfermo, tan delicado aún por la penosa enfermedad, de la cual apenas comienza á convalecer? No, señora; es enteramente preciso que usted deje á un lado miedos y timideces. Si ese joven quisiera en verdad darse la muerte, bien habría podido hacerlo, sin ponerse enfrente de usted, seguro de que su intento sería estorbado. Más bien me parece que trata de conmoverla con farsas y comedias, indignas de un hombre honrado. La enfermedad de su pobre Enrique debe darle á usted aliento y fuerzas para precipitar el término de una situación, que, si se prolonga, me temo que ya no sea tiempo de poder ocultar las insinuaciones amorosas de ese señor, el cual parece que, sin respeto ninguno á la amistad que lo ha ligado con el esposo de usted, se propone comprometer la reputación de usted y la paz de su hogar, sin miramientos ningunos, alegando el grande amor que usted le inspira.

Mientras encuentra usted un pretextó prudente para explicar la desaparición de esa persona, niéguese á recibirlo fingiendo enfermedad, ocupación, cansancio, etcétera. ¡Ojalá que muy pronto sepa yo que no ha vuelto á la casa de usted ese elemento de disgusto y compromiso, que se llama amigo de ustedes (Actualidades, página Para las Damas, sección "Consultas", 28 de noviembre de 1909 , p. 3 [cursivas añadidas]).

La consulta de mujeres casadas que eran pretendidas por amigos del marido permite identificar los imaginarios sobre la "naturaleza de los sexos", en los que las mujeres se aprecian vulnerables a la seducción y los hombres impulsivamente sexuales:

Carlota.- ¿Me pregunta usted cuál es la conducta que debe seguir con el joven que le ha declarado su amor, y al cual el esposo de usted distingue con sincera amistad? Creo que el caso no deja lugar á duda: en mi concepto, debe usted decirle á ese joven que no vuelva á la casa de usted, aunque esto traiga el inconveniente de que el señor su esposo note la desaparición del citado joven, y la extrañe, como es natural, dada la franca amistad que los ha unido. Para darle alguna explicación, usted buscará un pretexto, y, seguramente, lo halla pues las mujeres son siempre hábiles en esa clase de recursos (Actualidades, página Para las Damas, sección "Consultas", 5 de noviembre de 1909, p. 3).

Nada importa la forma respetuosa con que se le insinúa a usted. Nada tampoco el que usted se crea muy segura de sí misma $y$ de inquebrantable honradez; ni menos aún las amenazas de suicidio con que dicho joven pretende amedrentar á usted. No, señora; estos conflictos deben terminarse de una vez y destruirlos por su base. Tanto por él, que alejándose, olvidará, como por usted, evitando el peligro no sólo de que su esposo comprenda el sentimiento que su amigo tiene hacia usted, sino porque tampoco se debe poner á prueba el corazón, al contacto de una ternura tan viva (Actualidades, página Para las Damas, sección "Consultas", 5 de noviembre de 1909, p. 3 [cursivas añadidas]). 
La columna de Alina condensó una heteroglosia de valores morales laicos y saberes -legos y expertos-, en el marco de nuevas percepciones sociales definidas por los proyectos de progreso e higiene basados en la medicina higienista y eugenésica, las cuales también buscaron orientar las relaciones entregénero e intragénero de una clase social media e intermedia.

\section{¿Crisis o tribulaciones del corazón? Las Caras del amor y los Papeles de género}

Lo hombres también padecieron los dolores del amor, e igualmente se atrevían a escribir a Alina para pedir consejos en estos menesteres, lo que nos permite observar la expectativa y cumplimiento de los roles de género en las relaciones amorosas y lo que debían sentir de acuerdo con las reglas socioemocionales (Thoits, 1990) y los nuevos estilos emocionales (Sterns, 1994) vinculados a las identidades de masculinidad.

creo que debe desistir de su conquista amorosa. Las demostraciones de indiferencia que recibe usted por parte de la señorita á quien pretende, son ya demasiadas para poder pensar que sea simple recato y discreción. Una mujer, para juzgarse digna, no necesita dar á entender al hombre que se le muestra rendido y apasionado, que no le son gratas sus insinuaciones amorosas, como claramente lo indica todo lo que usted me cuenta en su larga carta. No, señor; también la mujer puede demostrar honesta y discretamente su simpatía cuando es pretendida con tanta lealtad y rectitud como usted lo ha hecho.

Siento vivamente tener que contestarle de tan desconsoladora manera; pero creo indispensable que procure usted retirar su pobre corazón de una batalla en donde tanto sufre, y por desgracia con todas las probabilidades de una segura derrota. Ponga usted su voluntad enérgica y varonilmente al servicio de una honrosa retirada, practicando lo que tan bella y juiciosamente nos dice aquel hermoso cantar español:

"Para encontrar un remedio

De amor en la cruda guerra,

No hay más que poner por medio

Mucho tiempo y mucha tierra."

Sinceramente le deseo que sus penas tengan un feliz término con el olvido ó con el triunfo (Actualidades, página Para las Damas, sección "Consultas”, 16 de octubre de 1909, p. 3 [cursivas añadidas]).

Llaman la atención las metáforas empledas por la consejera para conminar al hombre que le cuenta su desventura amorosa; la conquista infructuosa de una mujer es referida como una batalla imposible de ganar. Por ello lo exhalta a hacer uso de su enérgica voluntad varonil para aceptar juciosamente que no debe seguir en esa conquista.

Por otro lado, a la mujer le correspondía mostrar una aparente resistencia en la conquista, la cual era considerada prudente. El hombre debía saber interpretar esa apariencia para terminar o continuar en la "batalla de conquista". La resistencia de la mujer en el cortejo aparece como un rasgo de recato y discreción, que no siempre se interpretó como una auténtica negativa; los hombres debían aprender a interpretar y las mujeres a manejar a partir de las reglas del coqueteo. El tiempo de la negación resultaba fundamental para entender el verdadero mensaje de indiferencia que para el hombre debía significar el momento de la retirada.

Enamorado.- Siempre es mala consejera la pasión; y tiene usted la prueba de lo que le digo en lo que me cuenta en su carta. Nunca creí que la señorita á quien usted se dirige usara de tantos desdenes para tratarlo, por recato y modestia, como usted pensaba, pues para esto no necesita aparecer esquiva ó, más bien dicho, incorrecta.

Siempre me pareció que su conducta demostraba á usted muy claramente su indiferencia y absoluta resolución de no corresponder al amor de usted, y, por esto, le aconsejé que desistiera de su empresa.

Vuelvo a aconsejarle que llame en su auxilio á todas sus energías, aunque estén debilitadas, para librar una batalla, no ya con su empresa, sino contra usted mismo, á fin de conseguir una discreta retirada y un olvido completo (Actualidades, página Para las Damas, sección “Consultas”, 2 de diciembre de 1909, p. 3 [cursivas añadidas]).

La orientación de cómo debían conducirse los hombres en la relación amorosa resalta los rasgos de una masculinidad fundada en la fuerza de voluntad, la energía y la razón, mientras que de las mujeres se esperaba la represión y secundarización de sus deseos. 
Alina recibía preguntas acerca de lo que era el amor; en sus respuestas se identifica una concepción del amor que conllevaba la expectativa de un sentimiento que posibilitaría un vínculo eterno entre los amantes. El script amoroso basado en la complementariedad de almas o psiques, que se sostenía en expectativas sociales y el valor idealizado de lo que significaba el amor conyugal y, con ello, la domesticidad de la vida amorosa:

El amor me parece á mí que debe definirse según quien lo sienta. Para unos, es un atractivo exterior causado por la belleza; para otros es un flúido ó imán misterioso; hay quien opine que es un capricho; y me parece lo más acertado juzgarlo un sentimiento exquisito, provenido de la simpatía y ataduras psíquicas entre dos espíritus que se comprenden y completan. Mientras estos lazos no existan, no se le debe dar al sentimiento que se experimente, el nombre alto y delicado de "amor" (Actualidades, página Para las Damas, sección “Consultas”, 24 de noviembre de 1909, p. 8 [cursivas añadidas]).

La experiencia de celos fue motivo de consulta para Alina, quien respondía de manera puntual a las mujeres reproduciendo las ideas dominantes de la época respecto de que ese sentimiento era perjudicial para mantener el amor de un hombre. Se identifica una prescripción diferenciada por sexo en el manejo de los celos; las mujeres debían controlar esta emoción en procura de un amor perdurable (López, 2018). La columnista les advertía del peligro de los celos, si eran infundados, para mantener sus vínculos amorosos, y del necesario autocontrol para superarlos, lo que significó una racionalización de sus emociones (Hochschild, 1979). La recomendación de contención de los celos en las mujeres formó parte de los emotives en distintas publicaciones de la época (López, 2018).

Contra los celos, amiga mía, no hay más remedio que procurar adquirir un gran dominio sobre si misma, si son infundados; y si no lo son, cortar relaciones con la persona que causa esa tortura.

Si usted cree que su novio la quiere de verdad, y que, por tanto, no hay motivo para estar celosa, nunca le manifieste su desconfianza, pues este es el mejor medio para hacérsele usted desagradable. Es preciso, por el contrario, que se muestre alegre y confiada, pues los señores no soportan a las mujeres celosas. Si usted procura dominarse en ese sentido esté cierta de que su novio la querrá siempre.

¡Ojalá que mi consejo le sea benéfico y encuentre con él la tranquilidad y la dicha! (Actualidades, página Para las Damas, sección "Consultas", 23 de noviembre de 1909, p. 3 [cursivas añadidas]).

En las mujeres se depositó la responsabilidad del control de los celos y del cuidado de amores inconvenientes, que pusieran en entredicho el prestigio del hombre; la libertad de estos en las relaciones amorosas era un principio irrevocable. Para el caso de los hombres, los celos eran una emoción legítima, que en muchos casos dio lugar incluso al crimen de las mujeres (Flores, 2019). Los celos experimentados por las mujeres se vincularon con el control hacia los hombres, lo que aseguraba su ruina amorosa:

Como prueba de lo falso de esa suposición, tiene usted su carta tan rendida y apasionada, como tal vez nunca lo estuvo cuando podían verse con frecuencia. Así, pues, adquiera usted más confianza y no lo atormente con su incredulidad.

En cuanto á exigirle que no vaya á reuniones, bailes, etcétera, me parece indebida semejante petición. ¿Cómo es posible pretender que un joven militar no frecuente diversiones ni trate á nadie? No, amiga mía: semejante exigencia daría por resultado el justo disgusto de él, y perdería usted su estimación y su amor. Déjelo en libertad, pues, por otra parte, es el único medio de que usted dispone para comprobar la firmeza de su afecto (Actualidades, página Para las Damas, sección "Consultas", 15 de diciembre de 1909, p. 3).

Alina siempre alentaba a sus jóvenes consultantes para que tuvieran paciencia y esperaran el retorno de sus enamorados. Argumentaba que el amor y la lealtad de los hombres en la espera estaban garantizados; a ellas les tocaba aceptar la vida social de los hombres mientras debían aguardar pacientemente por su enamorado, cual Penélope.

\section{REFLEXIONES FINALES}

Se ha tratado de un primer acercamiento al tema -consultorios emocionales- en una época de cambios sociales en el México prerrevolucionario con el surgimiento de una prensa moderna, que deja ver la importancia de cultivar la sensibilidad. La prensa vehiculizó de manera pública y masiva la orientación de la 
vida del corazón, a través de iniciativas en forma de consejos y consultas. Distintos tipos de notas, columnas e información de la prensa moderna posibilitaron el andamiaje de una educación sentimental en la que se incrustaron los valores morales, los imperativos sociales, los roles de género, los valores de la clase media que se apegaba paulatinamente a los consejos de los expertos -médicos, pedagogos, filósofos y otros intelectuales-, lo que orientó estándares emocionales y emocionologías muy precisas, dirigidos a una clase social media. Por ello, se implementaron nuevos principios en el manejo diferenciado de las emociones de acuerdo con el sexo y clase social.

La vida íntima del corazón se fue entretejiendo de la mano de una voz experta, con la paulatina comercialización en espacios públicos como la prensa. La orientación emocional en la intimidad representa la inauguración de una nueva religión: la terapéutica, que se implementó a partir de consejeros informales o amistosos que ofrecían respuestas apegadas a la higiene, la moral y la educación de una naciente clase media. Los consejos ofrecidos por Alina, al igual que la información de otras publicaciones de la época en materia de amor y vida íntima en las mismas fechas, se apegaron a las expectativas sociales y de manera recursiva reforzaron los imaginarios de género promoviendo con ello la idea de complementariedad, base del modelo conyugal. La subordinación de la mujer en nombre del amor, la ternura y la maternidad se vincula con las emociones asociadas a lo femenino, mientras que la valentía, la energía y la voluntad fueron los rasgos psicológicos que caracterizaron a los hombres.

Los consultorios emocionales como categoría analítica han permitido demostrar cómo las emociones organizan también la vida social de acuerdo con el sexo, la edad, el estado civil, la profesión, y coadyuvan a mantener un orden en la interacción social. La construcción de la individualidad precisó de la moda, el agrado, la imitación, el consejo, el autocontrol de ciertas emociones, y, con ello, el advenimiento de un nuevo estilo emocional.

\section{ReFERENCiAS}

Bastian, J. P. (1989). La estructura social en México a fines del siglo XIX y principios del XX. Revista Mexicana de Sociologia, 51(2), 413-429. doi: https://10.2307/3540695

Bolufer, M. (2016). En torno a la sensibilidad dieciochesca. Discursos prácticas y paradojas. En M. L. Candau (Ed.), Las mujeres y las emociones en Europa y América. Siglos XVIII-XIX (pp. 29-56). Santander, Universidad de Cantabria.

Burkholder de la Rosa, A. (2009). El periódico que llegó a la vida nacional. Los primeros años del diario Excelsior (1916-1932). Historia Mexicana, LVIII(4),1369-1418. Recuperado de: https://www.redalyc.org/articulo.oa?id $=600 / 60015959003$

Castro, B., González, R., y Masera, M. (2013). La Imprenta Vanegas Arroyo, perfil de un archivo familiar camino a la digitalización y el acceso público: cuadernillos, hojas volantes y libros. Revista de literaturas populares, XIII(2), 491-503. Recuperado de: http://rlp.culturaspopulares.org/textcit.php?textdisplay=641

Cornejo, T. (2016). Representaciones populares de la vida urbana: ciudad de México, 1890-1930. Historia Mexicana, LXV(4), 1601-1651. doi: https://10.24201/hm.v65i4.3242

Flores, E. (noviembre, 2019). Los infortunios del amor y la exasperación de las pasiones en la nota roja de inicios del siglo XX: Reflexiones desde los estudios socioculturales de las emociones. Ponencia presentada en Primeras Jornadas Sobre Investigación en Ciencias Sociales y Humanidades 2019, Universidad de la Sierra (Oaxaca, México).

Foucault, M. (1990). Tecnologías del yo y otros textos afines. Barcelona: Paidós.

Garis, A. V., y Tardón, M. M. (2008). Corazones en conflicto. El consultorio sentimental en la prensa de Buenos Aires. Letra. Imagen. Sonido: Ciudad Mediatizada, (2), 89-105. Recuperado de: https://dialnet.unirioja.es/descarga/ articulo/5837849.pdf.

Hochschild, A. R. (2008). La mercantilización de la vida intima. Apuntes de la casa y el trabajo. Buenos Aires: Katz Editores.

Huertas, R. (2012). Historia cultural de la psiquiatría. Madrid: Catarata. 
Illouz, E. (2007). Intimidades congeladas. Buenos Aires/Madrid: Katz Editores.

Illouz, E. (2010). La salvación del alma moderna. Terapia, emociones y la cultura de la autoayuda. Buenos Aires: Katz.

Instituto Nacional de Estadística, Geografía e Informática (INEGI) (2000 [1985]). Estadísticas Históricas de México, Tomo I, INEGI: México.

Instituto Nacional de Estadística, Geografía e Informática INEGI (2010) Censo General de la República Mexicana para cuantificar por primera vez a la población. Estadísticas históricas de México. INEGI: México.

López, O. (2004). La profesionalización de la gineco-obstetricia y las representaciones técnico-médicas del cuerpo femenino en la medicina de la Ciudad de México (1850-1900) (Tesis doctoral). Centro de Investigaciones y Estudios Superiores en Antropología Social, Distrito Federal, México.

López, O. (2007). De la Costilla de Adán al útero de Eva. El cuerpo femenino en el imaginario Médico y social del siglo $X I X$. México: Facultad de Estudios Superiores Iztacala, Universidad Nacional Autónoma de México.

López, O. (2009). El dolor de Eva. La profesionalización del saber médico en torno al cuerpo femenino en la segunda mitad del siglo XIX en México. México: Facultad de Estudios Superiores Iztacala; Universidad Nacional Autónoma de México.

López, O. (2011). La pérdida del paraiso. El lugar de las emociones en la sociedad mexicana entre los Siglos XIX y XX. México: Facultad de Estudios Superiores Iztacala, Universidad Nacional Autónoma de México.

López, O. (2018). Las cartas amorosas de la imprenta de Vanegas Arroyo en la educación sentimental en México entre 1900 y 1930. Ponencia presentada en Coloquio Las pasiones en la prensa. Proyecto I+D+I CSO2015-66667-R Cambios en la empresa periodistica: la estrategia del sensacionalismo. Su emergencia histórica en España y América, (Argentina, México y Costa Rica). Facultad de Estudios Superiores Acatlán, UNAM (Santa Cruz Acatlán, México).

López, O. (2019). Extravios del alma mexicana. Patologización de las emociones en los diagnósticos psiquiátricos (1900-1940). México: Facultad de Estudios Superiores Iztacala, Universidad Nacional Autónoma de México.

Méndez,J. (2001) La prensa opositora al maderismo, trinchera de la reacción. El caso del periódico El Mañana. Estudios de Historia Moderna y Contemporánea de México, 21,31-57. doi: https://10.22201/iih.24485004e.2001.021.3 038

Ortiz, Á. M., y Duarte, M. R. (2010). El periodismo a principios del siglo XX (1900-1910). Pilquen, Sección Ciencias Sociales, Dossier Bicentenario, XII(12), 1-9.

Pedraza, Z. (2000). La educación sentimental y el descubrimiento de sí mismo. En S. Castro (Ed.), La reestructuración de las ciencias sociales en América Latina (pp. 311-325). Bogotá: CEJA.

Reddy, W. (2001). The Navigation of Feeling. A Framework for the History of Emotion. Cambridge and New York: Cambridge University Press.

Rocha, M. E. (1995). El consultorio sentimental. Paradigmas y comportamientos amorosos. En J. Blanco et. al (Ed.), Cuidado con el corazón. Los usos amorosos en el México moderno (pp. 143-162). México: Instituto Nacional de Antropología.

Rose, N. (1996). Governing the Soul. The Shaping of the Private Self. Londres: Free Association Books.

Rose, N. (1999). Saving the Soul. The shaping of the private self. London: Free Association Books.

Simmel, G. (2014). Filosofía de la coquetería y otros ensayos. México: Ediciones Coyoacán.

Speckman, E. (2001). Pautas de conducta y códigos de valores en los impresos de Venegas Arroyo. En R. Olea (Ed), Literatura mexicana del otro fin de siglo (pp. 425-448). México: El Colegio de México.

Stepan, N. (1991). The hours of eugenics. Race, Gender, and Nation in Latin America. London: Cornell University Press. Sterns, P. (1994). American Cool. Constructing a Twentieth-Century Emotional Style. New York: New York University.

Sterns, P. \& Sterns, C. (1985) Emotionology: Clarifying the History of Emotions and Emotional Standards, American Historical Review, 90(4). 813-836.

Thoits, P. (1990). Emotional deviance: Research Agendas. En T. Kemper (Ed.), Research Agendas in the Sociology of Emotions (pp. 180-203). Nueva York: State University of New York Press. 
Urías, B. (2007). El 'hombre 'Nuevo' de la posrevolución. Letras Libres, (101), 59-61. Recuperado de https://www.l etraslibres.com/mexico/el-hombre-nuevo-la-posrevolucion.

Williams, R. (2009). Marxismo y literatura. Buenos Aires: Las cuarenta.

\section{Fuentes Primarias}

Alina (octubre a diciembre de 1909). Para las Damas. Actualidades.

Barreda, H. (1 de enero de 1909). Estudio sobre el feminismo. I. Advertencia preliminar. Revista Positiva. Orden y progreso, 103, 1-10.

Barreda, H. (26 de febrero de 1909a). Estudio sobre El feminismo. II. Organización física, intelectual y moral que es característica de la mujer. Revista Positiva. Orden y progreso, 105, 75-86.

Barreda, H. (26 de marzo de 1909b). Estudio sobre El feminismo. III. Influencia de la educación sobre la naturaleza de la mujer. Revista Positiva. Orden y progreso, 106, 107-126.

Barreda, H. (26 de abril de 1909c). Estudio sobre El feminismo. IV. Caracteres de la situación social que la evolución humana ha venido preparando a la mujer. Conformidad de esa situación con los datos psicológicos que proporciona la exploración biológica. Solución positiva del problema social de la mujer. Revista Positiva. Orden y progreso, 107, 182-217.

Barreda, H. (21 de mayo de 1909d). Estudio sobre El feminismo. V. Las tendencias feministas son el necesario resultado del desorden intelectual y moral que es propio de la situación revolucionaria por que atraviesan las sociedades modernas. Revista Positiva. Orden y progreso, 108, 225-238.

Barreda, H. (21 de junio de 1909e). Estudio sobre El feminismo. VI. Del feminismo en México. Psicología de la mujer mexicana. -Ideal perseguido por nuestros feministas-. Consecuencias domésticas y sociales de la llamada americanización de la mujer mexicana-. Sentido en que debe impulsarse en nuestro país la elevación de la condición social del sexo femenino. Revista Positiva. Orden y progreso, 109, 263-293.

\section{Notas}

1 El texto es resultado directo del Proyecto de Investigación "El amor romántico: genealogía de un régimen sentimental en México entre 1900-1950", financiado por el Programa de Apoyo a Proyectos de Investigación e Innovación Tecnológica (PAPIIT), de la Dirección General de Asuntos del Personal de la Universidad Nacional Autónoma de México (DGAPA-UNAM), con el registro IN300817.

2 Profesora titular “C”, TC, de la Facultad de Estudios Superiores Iztacala-Universidad Nacional Autónoma de México (FESI-UNAM), integrante del Sistema Nacional de Investigadores (SNI), Nivel 2, co-coordinadora de la Red Nacional en los Estudios Socioculturales de las Emociones (RENISCE) https://renisce.com/

3 "Entidad naturalmente única y discreta, en la que los límites del cuerpo, que por definición encierran la vida interior de la psiquis es donde se inscriben las experiencias de la biografía individual” (Rose 1996, p. 23).

4 La emocionología (emotionology) es una estrategia analítica propuesta por los Sterns (1985), que se caracteriza por el estudio de la variación en la manifestación y contenido de las emociones tomando en cuenta el lugar y el tiempo.

5 La noción de un hombre nuevo alude al imaginario social que refiere el perfeccionamiento moral y físico de la "humanidad regenerada, racialmente homogénea y sin diferencias internas (...) idénticos entre sí” (Urías, 2007, p. 59).

6 Reddy (2001) se refiere al concepto de refiere expresiones emocionales como actos de habla que promueven una performatividad en los sujetos

7 Esta categoría acuñada por Nikolas Rose (1999) refiere la inclusión del psicoanálisis, la psiquiatría, la psicología y las psicoterapias.

8 Incluye a las publicaciones periódicas, impresos, hojas volantes - papeles sueltos de carácter informativo-, publicaciones por entrega, gacetas, gacetillas.

9 De acuerdo con el censo de 1895, de más de 12 millones de habitantes, seis millones de mexicanos mayores de 15 años no sabían leer ni escribir (INEGI, 2010).

10 Periódico dirigido por Rafael Reyes Spíndola en el último periodo del porfiriato; tuvo como meta ofrecer un semanario a la altura de las ediciones europeas y norteamericanas dirigido a las clases acomodadas de la sociedad mexicana (Burkholder, 2009). 
Oliva López Sánchez. Los Consultorios emocionales: nOtaS PARA Un ANÁLisis de LA EDUCACión SENTIMEN...

11 Sobre publicaciones dirigidas a las clases populares y la educación sentimental en México, puede consultarse López (en prensa).

12 Aparecía los primeros viernes de cada mes y tenía un costo de cinco centavos. En 1909 el salario mínimo en México en la zona centro en peso corriente fue de 0.36602 (INEGI, 2000[1985]). Esto significa que el costo de esta publicación podía comprometer más del 10 por ciento del salario diario de trabajadores (servicios, jornaleros, comercio). Por estos datos puedo suponer que era distribuido entre un sector social medio y alto.

13 Su línea editorial se explicita en la siguiente nota: "Todo periódico civilizado necesita del periódico absolutamente libre. Porque sólo un periódico de esa índole puede decir la verdad, y, en la vida moderna, el pueblo está ávido de verdades" (p. 1). Actualidades, “'Actualidades' Es ya un Diario. Queremos hacer un periódico digno de la confianza de sus lectores y sus anunciantes”, Tomo II, Núm. 1, 15 de octubre de 1909, p. 1.

14 Sobre consultorios sentimentales en México en el siglo XX, véase Rocha (1995) y Rodríguez (2007).

\section{BY-NC-SA}

